\title{
Synthesis of 1,1'-oxalyldibenzotriazole, study of the kinetic and thermodynamic features of its hydrolysis and prediction of biological activity
}

\author{
C Pyotr P. Purygin, ${ }^{1}{ }^{+}$Konstantin V. Milyutin, ${ }^{1}$ Olga B. Grigoryeva, ${ }^{2}$ and Yury P. Zarubin ${ }^{1}$ \\ ${ }^{1}$ Chair of Inorganic Chemistry. Samara National Research University. Moskovskoe Ave., 34. Samara, \\ 443086. Samara Region. Russia.Phone: +7 (846) 334-54-59. E-mail: puryginpp2002@mail.ru \\ ${ }^{2}$ Department of Chemistry, Chemical Processes and Technologies. Togliatti State University. \\ Belorusskaya St., 14a. Togliatti, 445020. Samara Region. Russia. \\ Phone:+7 (903)330-17-14.E-mail: groly@yandex.ru
}

\begin{abstract}
*Supervising author; ${ }^{+}$Corresponding author
Keywords: 1,1'-oxalyl dibenzotriazole, synthesis, hydrolysis, alcoholysis, aminolysis, kinetics, stability in media containing nucleophiles, hydrolysis rate constant, alcoholysis rate constant, aminolysis rate constant, half-life, thermodynamic characteristics, calculations, quantum-chemical, molecular mechanical, biological activity, prediction.
\end{abstract}

\footnotetext{
Abstract

The article describes a two-step method for the synthesis of 1,1'-oxalyl dibenzotriazole (bis( $1 \mathrm{H}$ benzotriazol-1-yl)ethane-1,2-dione) from benzotriazole via 1-trimethylsilylbenzotriazole, followed by reaction with oxalyl chloride; the yield of the final product is $87 \%$. The kinetics of hydrolysis, alcoholysis and aminolysis of 1,1'-oxalyldibenzotriazole was studied in the systems acetonitrile - water $(9: 1)$, acetonitrile methanol $(9: 1)$, acetonitrile - diethylamine $(9: 1)$ at $25^{\circ} \mathrm{C}$, and also by the equation Arrhenius values of the activation energy in the reactions of hydrolysis, alcoholysis, and aminolysis of 1,1'-oxalyl dibenzotriazole were calculated. To study the thermodynamic features of the reactions of obtaining this compound in the Spartan'14 1.1.4 program, a number of thermodynamic characteristics were calculated, determining the spontaneous and exothermic nature of the process.

For the 1,1'-oxalyl dibenzotriazole molecule, possible conformers were found in the Molecular Operating Environment 2014.0901 software, for which the surfaces of nucleophilic susceptibility were calculated in the SCIGRESS Modeling 3.1.4 software.

The structure of 1,1'-oxalyl dibenzotriazole was confirmed by IR and ${ }^{1} \mathrm{H}$ NMR spectroscopy. The program PASS Professional 2007 predicted the most likely types of biological activity of the studied compounds. The most significant types of biological activity are in relation to renal diseases, anti-neurotoxic, anti-acid, anti-inflammatory. The obtained data allow us to choose the optimal conditions for the synthesis of 1,1'oxalyl dibenzotriazole and to conclude that it is low stability in nucleophilic-containing media.

\section{References}

[1] H. Nagayoshi, K. Kakimoto, S. Takagi, Y. Konishi, K. Kajimura, T. Matsuda. Environ Sci. Technol. 2014. Vol.49. P.578-587.

[2] S.L. Zhang, J.J. Chang, G.L.V. Damu, R.X. Geng, C.H. Zhou. Med. Chem. Comm. 2013. Vol.4. P.839846.

[3] M.C. Becerra, N. Guinazu, L.Y. Hergert, A. Pellegrini, M.R. Mazzieri, S. Gea, I. Albesa. Exp. Parasitol. 2012. Vol.131. P.57-62.

[4] V.M. Kumar, V. Sanjay. Bioorg. Med. Chem. Lett. 2008. Vol.18. P.5640-5642.

[5] S. Sakthi, S. Periyasamy, K. Sampath, E.D. Clercq. Int. J. Pharmacy. Pharm. 2010. Vol.2. P.71-79.

[6] L. Birkofer, P. Richter, A. Ritter. Chem. Ber. 1960. Vol.93. P.2804-2809.

[7] H.A. Staab, G. Seel. Justus Liebigs Annalen Der Chemie. 1958. Vol.612. P.187-193.

[8] https://www.chemicalbook.com/ProductChemicalPropertiesCB9400519_EN.htm
} 